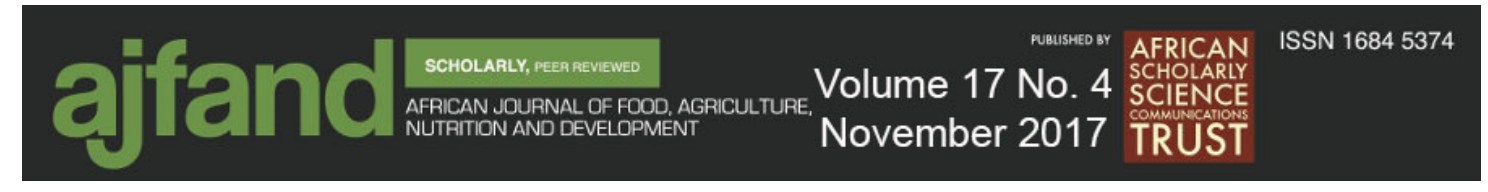

\title{
RISK FACTORS ASSOCIATED WITH STUNTING AMONG INFANTS AND YOUNG CHILDREN AGED 6 - 23 MONTHS \\ IN DEDZA DISTRICT OF CENTRAL MALAWI
}

$$
\text { Geresomo } \mathrm{NC}^{1^{*}} \text {, Mbuthia EK }{ }^{1} \text {, Matofari } \mathrm{JW}^{2} \text {, and AM Mwangwela }{ }^{3}
$$

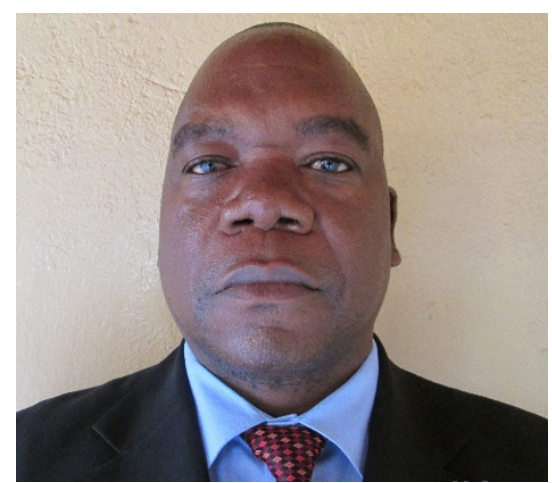

Numeri Geresomo

*Corresponding author email: ngeresomo@gmail.com / numerigeresomo@yahoo.com

${ }^{1}$ Department of Human Nutrition, Egerton University, P.O Box 536-20115, Egerton, Kenya

${ }^{2}$ Department of Dairy and Food Science and Technology, Egerton University, P.O Box 536-20115, Egerton, Kenya

${ }^{3}$ Department of Food Science and Technology, Lilongwe University of Agriculture and Natural Resources, P.O. Box 219, Lilongwe, Malawi 


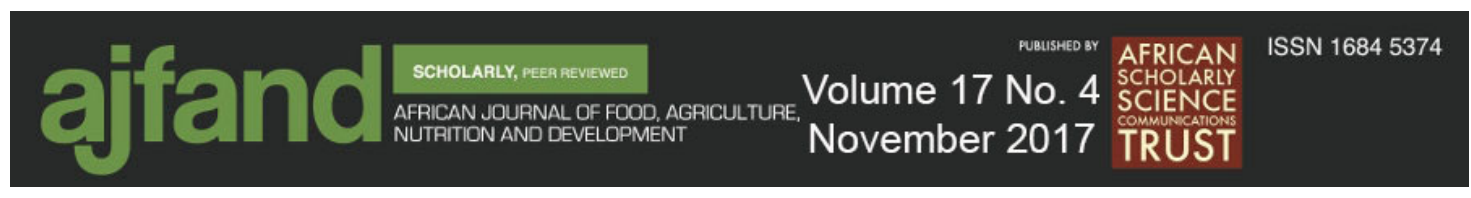

\section{ABSTRACT}

The prevalence of stunting is high in Malawi, affecting about one third $(31.2 \%)$ of children aged 6-23 months. Persistent inappropriate feeding practices are some of the major causes of stunting in young children. This study was conducted to determine risk factors associated with stunting among infants and young children aged 6-23 months in Dedza district in Central Malawi. A cross-sectional study was conducted in 12 villages in Mayani Extension Planning Area (EPA), targeting households with children aged 623 months. A structured questionnaire was used to collect data from the primary caregivers on household socioeconomic characteristics, household food availability, dietary diversity, responsive feeding practices among mothers and caregivers, age of introduction of complementary foods, frequency of feeding, types of foods and dietary diversity of children. Anthropometric data (weight and recumbent length) for children were measured using standard procedures. The Multivariate Logistic Regression Analysis was performed to study the independent associations of various determinants on prevalence of stunting with prevalence of stunting as a dependent variable. A total of 303 households were sampled randomly; mothers and caregivers were interviewed and 306 children were assessed for nutritional status. Introduction of complementary food varied among mothers, 9.3\% introduced earlier than 6 months, $71.1 \%$ at 6 months and $10.2 \%$ later than 6 months. Dietary diversity was low but increased significantly with age categories of children, $2.9 \%$ for children $6-8$ months, $15.5 \%$ for $9-11$ months and $24.6 \%$ for $12-23$ months $(\mathrm{p}<0.01)$. Minimum meal frequency was significantly $(\mathrm{p}<0.001)$ higher in children 6-8 months $(58.7 \%)$ than in children 12-23 months (1.9\%). Overall, out of the 306 children $47.1 \%$ [95\% CI (41.6-53.1)] were stunted. Stunting was significantly different between male $[54.5 \%$; 95\% CI (47.0-63.5)] and female $(39.5 \%$; 95\% CI (31.4-47.6)] children. Age of child when complementary feeding was started [AOR: $0.138 ; 95 \%$ CI $(0.22-0.88)$ ], number of young children in the household [AOR: $2.548 ; 95 \%$ CI (1.304-4.981)] and teenage mothers [AOR: 1.265; 95\% CI (0.379-1.724)] were significant independent predictors of stunting. It can be concluded that prevalence of stunting is high among infants and young children in Dedza district. Training mothers and caregivers on recommended age of introducing complementary food to a child, composition of such food, dangers of teenage pregnancies and importance of child spacing should form part of nutrition education.

Key words: Nutritional status, dietary diversity, complementary feeding, meal frequency, responsive feeding 


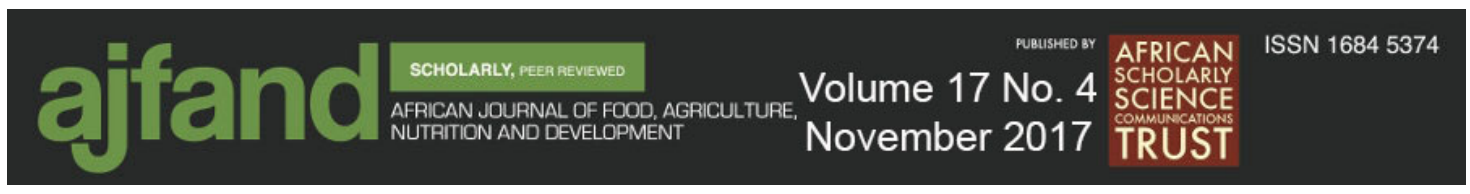

\section{INTRODUCTION}

The World Health Organization (WHO) puts the average rate of stunting [0-59 months] in sub-Saharan Africa at 40\% [1]. Malawi is one of the countries with the highest rates of stunting in Africa affecting 31.1\% of children aged 6-23 months [2]. Anemia affects $54.8 \%$ of children $[2,3]$ and Acute Respiratory Infections (ARI) affect $8.5 \%$. Persistent inappropriate complementary feeding and poor childcare practices are some of the major causes of stunting. The indicators for appropriate infant and young child feeding recommended by WHO include introduction of solid, semi-solid or soft foods, minimum dietary diversity, minimum meal frequency and minimum acceptable diets [4]. Less than one in four children 6-23 months worldwide meets the criteria for minimum dietary diversity and feeding frequency. In Malawi, the 2015 Demographic and Health Survey results showed that only $8 \%$ of children $6-23$ months were reported to have received minimum acceptable diets [2].

The prevalence of stunting [ $<6$ to 59 months] in Malawi is highest in the southern region $(47.6 \%)$ followed by the central region $(47.2 \%)$ and the northern region $(44.7 \%)$. In the central region, Dedza district has the third highest prevalence of stunting (51.1\%) among under-five children. Poor complementary feeding practices coupled with common childhood illnesses $[2,5]$ such as acute respiratory infections (ARI), diarrhea, malaria and measles, which affect large numbers of children in Malawi, remain the immediate causes of under-nutrition. Trends of prevalence of stunting by age category showed that children aged 18-23 months were the most affected (61.3\%) followed by those aged $24-$ $35(56.0 \%)$ and 36-47 months (51.6\%) [2]. The persistent high chronic under-nutrition in Malawi may be associated with low family incomes, poor child feeding and care practices and lack of knowledge in appropriate food processing and utilization $[1,6]$

The typical local complementary food in Malawi is porridge made from maize flour or other staples such as millet, sorghum or cassava, and is composed of $7 \%$ dry matter and provides $7 \mathrm{Kcal}$, which is lower than the recommended $10 \mathrm{Kcal}$ per $100 \mathrm{~g}$ of body weight [7]. Occasionally, other foods are sometimes added to the porridge. In some cases commercial infant foods are given to children by some few families that may afford [8]. However, foods from animal sources, fruits and vegetables are rarely added to complementary foods [9].

Dedza district is frequently affected by droughts and flooding, which result in reduced food production and increased household food insecurity. Long episodes of drought may also lead to food losses due to outbreaks of crop pests and diseases. Despite Dedza being one of the districts with the high prevalence of stunting, there is hardly any information on how household socioeconomic characteristics, childcare and complementary feeding practices among mothers or caregivers of children aged 6 to 23 months could be associated with stunting. Elucidating information on household socioeconomic characteristics such as age of the mother, age of introduction of complementary foods to children, meal frequency, dietary diversity, common childhood illnesses and mother's knowledge on feeding practices would be useful for development of nutrition education and extension materials to contribute towards reduction and prevention of stunting. 
This study forms a baseline for research to develop a strategy for preventing contamination and poor hygiene in handling complementary foods in Mayani EPA in Dedza district. The aim of this study was to determine risk factors associated with stunting among young children aged 6-23 months in Dedza district of central region of Malawi.

\section{MATERIALS AND METHODS}

\section{Study Design and Area}

A cross-sectional study was conducted in Mayani Extension Planning Area (EPA) in Dedza district to determine complementary feeding practices among mothers of children aged 6 to 23 months and to assess the nutritional status of the children. Dedza district is in the central region of Malawi with an estimated population size of 768,000. The district has two agro-ecological zones namely: Dedza Hills and Lilongwe-Kasungu Livelihood zone plain. The study area is located in the hilly areas to the North-West of the district where a project named "Capacity Building for Management of Climate Change" was being implemented by the sponsors of this study. This area was, therefore, selected for this study to contribute to the output of the said project.

\section{Study Population, Sample size and Sampling Techniques}

Mothers and their children aged 6-23 months were targeted for this study. Children aged 6-23 months were chosen because this age category is within the first 1,000 days of the life of a child, which are critical for child growth and development [10]. These are also the ages when the children are vulnerable to various infections due to the introduction of complementary foods after exclusive breastfeeding.

Household sample size was determined using a standard formula for cross-sectional studies [11] and 303 households were selected from 12 villages randomly sampled from a list of 62 villages using a systematic random sampling technique. The study was household-child based and the inclusion criteria included permanent residence of mother or caregiver of the child in the community and presence of a child aged 6-23 months in the household. Households with no children or with children aged below 6 months, children of visitors and households with seriously sick children were not considered for inclusion in the study.

A pretested and validated questionnaire was used to collect information from mothers and caregivers on: household characteristics, food availability, dietary diversity, introduction of solid, semi-solid or soft foods, minimum acceptable diet, meal frequency, responsive feeding practices and child morbidity. The questionnaire was translated from English into a local language, Chichewa to enable respondents understand the questions. A 24-hour dietary recall questionnaire was used to collect information on foods consumed by mothers, caregivers and children. Amounts of foods consumed by children were estimated using local measuring utensils. Quantities of foods consumed were calculated and entered into NutriSurvey for analysis. Maternal knowledge on complementary feeding was assessed by using six knowledge questions on recommended age of child for introducing complementary foods, why introducing complementary foods at six months is important, correct frequency of feeding children of different age 
categories and responsive feeding. Mothers or caregivers who responded correctly to $<50 \%, 50$ to $70 \%$ and $>70 \%$ of the knowledge questions, were considered as having poor, fair and good knowledge of child feeding practices, respectively. Anthropometric measurements (weight and length of children) were taken using weighing scales (SECA $881 \mathrm{U}$ ) and length boards, respectively. The occurrence of specific morbid states of the children in the previous two days and two weeks preceding the survey were collected and used as a surrogate measure of the type, frequency and persistence of disease burden in the communities.

\section{Data Analysis}

Data from the households were analysed using Statistical Package for Social Sciences (SPSS) Version 20. Anthropometric data were analysed in WHO Anthro package to derive nutrition indices (height for age) and determine whether a child was stunted or not. All children whose z-scores for height for age (HAZ) were $<-2$ to -3 z-scores of the reference mean were classified as moderately stunted while those whose $z$-scores for HAZ were <-3 z-scores of the reference mean were classified as severely stunted [12]. Descriptive statistics were generated for the household characteristics and cross tabulations were ran to correlate variables. The Chi-square test was used to determine associations between household demographic characteristics and child feeding practices. To study the independent associations of various indicators of complementary feeding on prevalence of stunting, multivariate Logistic Regression analysis was performed. The dependent variable was stunted $(<-2 \mathrm{SD}$, coded 1$)$ or not stunted $(-2 \mathrm{SD}$ and above, coded 0 ) while indicators of complementary feeding such as introduction of solid, semi-solid or soft food, minimum dietary diversity, minimum meal frequency and minimum acceptable diet were the independent predictors of stunting. Other independent predictors used in the Multivariate Logistic Regression analysis were household social demographic characteristics such as age of the mother, number of under five children in the household, sex of the child and maternal education. Using adjusted odds ratios at $95 \%$ confidence interval $(\mathrm{CI})$, risk factors associated with stunting were identified.

Dietary intake data were analysed using NutriSurvey for Windows (C) 2007 computer package. Food Composition Tables for East and Southern Africa were used to determine nutrient contents of foods not found in NutriSurvey. The values were entered into NutriSurvey to form part of the dataset for this study. Dietary diversity scores were calculated for food intakes and interpreted using cut-off points recommended by FAO. Diets from three or less food groups were considered to have no diversity, diets comprising four to five food groups were considered to be of medium diversity and diets prepared from six or more food groups were classified as being of high diversity $[13,14$, $15]$.

\section{Ethical Consideration}

Ethical approval for the study was obtained from the National Health Sciences Committee (NHSC) of Ministry of Health in Malawi under the Approval Number NHSRC \# 15/4/1432. Oral consent was obtained from all mothers and caregivers who participated in the study. 


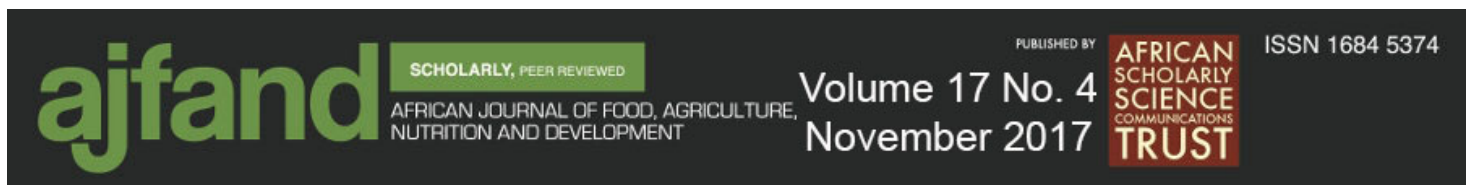

\section{RESULTS}

\section{Demographic and Socioeconomic Characteristics of Sampled Mothers and Children}

Predominantly, $95.7 \%$ of respondents were biological mothers of the children and the rest were caregivers. The majority $(89.1 \%)$ of households were male-headed whose mean age was $32.3 \pm 10.6$ years. The mean age of mothers was $26.5 \pm 7.0$ years and the youngest being 16 years old (Table 1$)$. The majority of mothers $(63.7 \%)$ were aged 21 to 34 years. The mean household size was $5.0 \pm 1.8$ persons and was higher than the national mean household size of 4.6 [16]. The average number of under-five children per household was $1.42 \pm 0.59$ and the mean number of children given birth to by a mother was $3.2 \pm 2.1$. Predominantly, $65.3 \%$ of the household heads and $71.6 \%$ of caregivers attained only primary school education, an indication of low education attainment. Slightly over half $(53.5 \%)$ of the mothers and caregivers could read or write and over $97 \%$ are smallholder farmers while $3 \%$ were involved in small businesses.

\section{Household Food Availability and Consumption}

The majority of households produced their own food. Maize, a staple food for the communities, was available in $87 \%$ of the households from their own production. Households also depended on markets as sources of maize $(11.2 \%)$, groundnuts $(3.3 \%)$ and soybeans $(9.7 \%)$. Maize and groundnuts were also accessed through food aid $(0.4 \%$ for maize and $2.2 \%$ for groundnuts) and Food- for- Work programme $(0.7 \%)$. The most commonly eaten food groups were cereals $(99 \%)$ and leafy vegetables $(63.8 \%)$. Sources of vitamin A were mainly dark green leafy vegetables $(57.7 \%)$ and legumes $(55.3 \%)$. Consumption of fruits such as pawpaw, bananas and oranges which are good sources of vitamin $A$, Vitamin $C$ and minerals was very low (10\%). About $15.6 \%$ of mothers and caregivers rarely consumed fish and less than $10 \%$ consumed flesh meat and eggs. Only $17.8 \%$ of mothers and caregivers had diversified diets, an indication of limited variety of foods in the study area.

\section{Complementary Feeding Practices among Households}

The majority of mothers $(80.5 \%)$ introduced complementary foods to their children at the right age of six months. However, 9.3\% introduced complementary foods earlier than six months. Over one tenth of mothers and caregivers $(10.2 \%)$ introduced complementary foods later than the recommended age of six months. Mothers who introduced complementary food at the right age of six months demonstrated knowledge of correct meal frequency for a particular age of the child. The majority of mothers and caregivers $(60.4 \%)$ had fair knowledge of complementary feeding while only $3.3 \%$ had good knowledge.

The most common complementary foods were from grains, roots and tubers (Table 3). Over $90 \%$ of complementary foods were from cereals only (porridge). In some cases, mothers added legumes and nuts $(51.1 \%)$ comprising groundnuts $(50.2 \%)$, soybeans $(4.6 \%)$, and also cooking oil (2\%) and leafy vegetables (1\%) to the porridge. Addition of other foods to complementary foods increased as the ages of children also increased. There were significant differences in consumption of vitamin A rich vegetables across the age categories of children $(11.4 \%, 39.4 \%$ and $50.3 \%$ for ages $6-8,9-11$ and $12-23$ 
months, respectively) (Table 3 ). The majority of children $(81.8 \%)$ consumed porridge while $18.2 \%$ consumed nsima. Nsima is a thick porridge prepared with maize flour with $25 \%$ solids and $75 \%$ water and eaten with vegetable or meat sauces. Provision of snacks to children was not common and only bananas $(8.6 \%)$, baked products $(6.9 \%)$ and boiled potatoes $(6.3 \%)$ were given as snacks.

Meal frequency was low among the children especially those who had stopped breastfeeding. The majority of children $(51.5 \%)$ were fed at least once or twice per day, $38.9 \%$ three times and only $2.6 \%$ were fed four times per day. Consumption of minimum meal frequency differed significantly among children of different age categories. Younger children were fed more frequently than older ones. More mothers with young children (6-8 months) knew the correct feeding frequency than those with older children (12-23 months). Only $18.2 \%$ of the children received minimum or more meal frequency with $58.7 \%$ of children $6-8$ months receiving minimum or more meal frequency than those aged $9-11$ months $(17.5 \%)$ and 12 - 23 months (1.9\%). Active or responsive feeding was practiced by $22.9 \%$ of the caregivers. The common practices included giving the child a variety of foods $(0.6 \%)$, adding tasty foods to complementary food $(0.9 \%)$ and forcing the child to eat $(6.1 \%)$. Knowledge of mothers or caregivers on correct frequency of feeding the child varied with the age of the child.

The majority of children (82.5\%) had low dietary diversity and the proportion of children with high dietary diversity differed significantly as the age of the child increased $(2.9 \%$ for 6-8 months, $15.2 \%$ for $9-11$ months and $24.6 \%$ for $12-23$ months) (Table 4). Households with access to a diversity of foods prepared more diversified complementary foods than those who did not have diversified foods. The mean intakes of protein $(38.6 \%$ of RDA) and fat (16.1\% of RDA) among the children were low while mean intakes of energy (50.3\% of RDA), vitamin A (71.7\% of RDA) and iron (52.6\% of RDA) were high. On average, children met $57.7 \%$ of Recommended Daily Allowance for energy requirements, $38.6 \%$ of RDA for protein, $74.6 \%$ of RDA for vitamin $\mathrm{A}$ and $55.9 \%$ of RDA for iron while nutrient intakes varied with age categories of the children (Table 5).

\section{Child morbidity and care practices}

The common illnesses among the children included malaria, diarrhoea and cough. Over periods of two days and two weeks before the study, $28.7 \%$ and $25.8 \%$ of the children had diarrhoea, respectively. Coughing was reported in $41.9 \%$ and $36 \%$ of the children. Fever with difficult breathing, a proxy for pneumonia, affected $4.3 \%$ and $6.6 \%$ of the children. Mothers and caregivers of children who had diarrhoea took different actions to manage the diarrhoea which included taking the child to a medical facility for treatment $(41.6 \%)$, giving the child home- made fluids $(25.5 \%)$ and giving medicines that were bought from local shops $(4.8 \%)$. One fifth $(20.8 \%)$ of mothers did not take any action to manage the diarrhoea (Figure 1). 

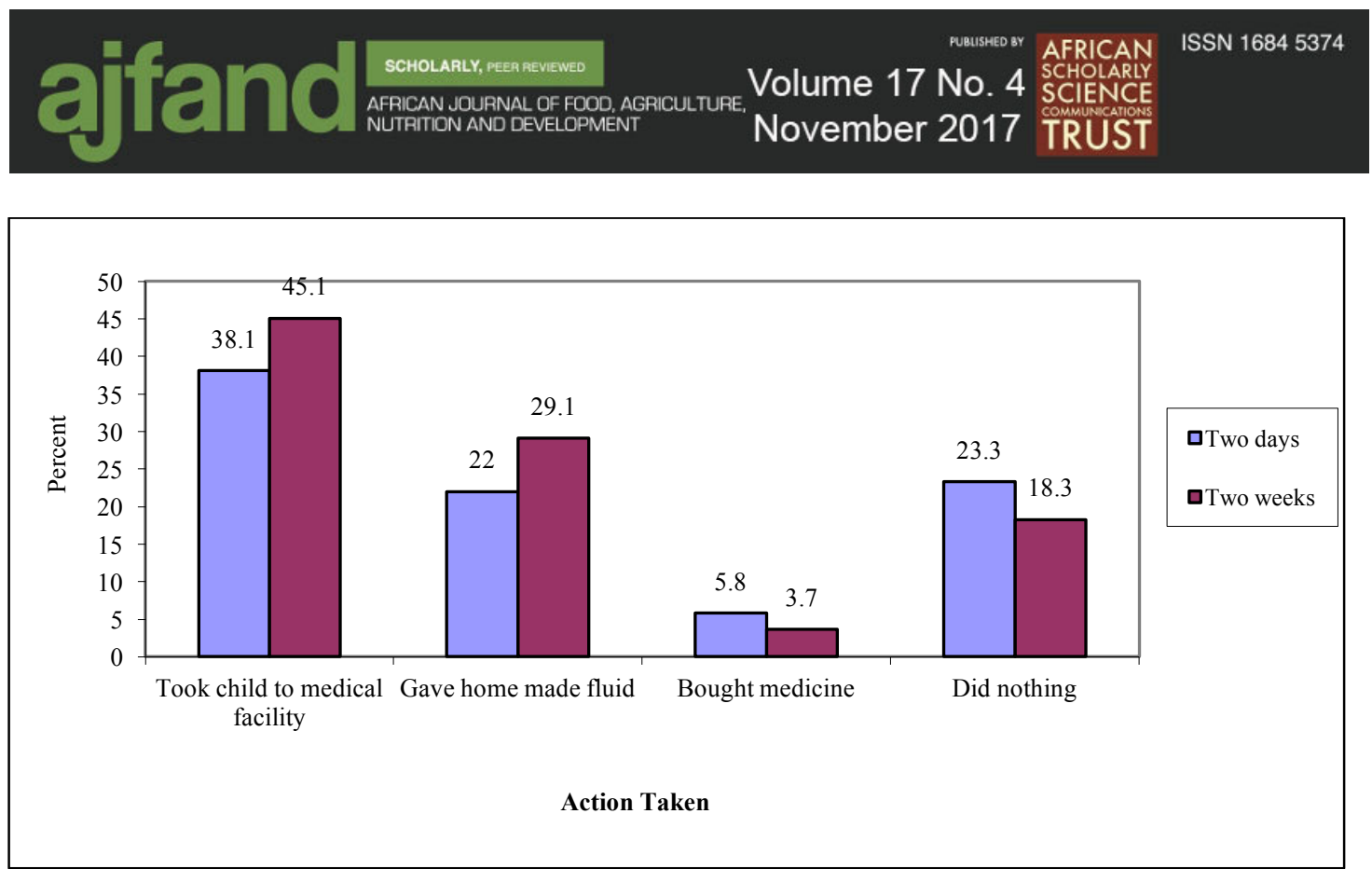

Figure 1: Management of diarrhoea by mothers and caregivers

\section{Nutritional status of children}

Analysis of nutritional status for children aged 6-11 months and 12-23 months showed that prevalence of stunting was $36.7 \%$ and $54.5 \%$, respectively. Overall, prevalence of stunting was 47.1\%; [95\% CI (41.6\%-53.1\%)] among all children (Table 6). Stunting was significantly different between male $[54.5 \%(47.0 \%-63.5 \%)]$ and female $[39.5 \%$ (31.4\%-47.6\%)] children (Table 6). Overall, prevalence of stunting was higher among male children than female children. Similar findings were reported in a study conducted in Southern Ethiopia [17].

\section{Factors associated with stunting among the children}

The prevalence of stunting was significantly associated with variables such as age of introduction of solid, semi-solid or soft foods to the child [AOR: 0.138 ; 95\% CI $(0.22-$ $0.88)$ ], number of young children in the household [AOR: 2.548; 95\% CI (1.304-4.981)] and teenage mothers, those aged 19 years and below [AOR: 1.265 ; 95\% CI $(0.379-$ 1.724)] (Table 7). Variables such as maternal education, minimum dietary diversity, minimum meal frequency and minimum acceptable diet did not show statistical association with stunting.

\section{DISCUSSION}

This descriptive cross- sectional study was aimed at determining risk factors associated with stunting among children aged 6 to 23 months in Dedza district in central region of Malawi.

The study showed that the majority of mothers and caregivers had fair knowledge of appropriate complementary feeding. Though the majority of mothers introduced complementary foods at the right age of six months, there were some who introduced complementary foods earlier than six months and others who introduced complementary foods later than six months (Table 2). Mothers got information on recommended complementary feeding from health personnel, grandmothers and friends (peers). About 
one-fifth of mothers or caregivers did not have access to information on recommended child feeding practices. Poor maternal knowledge on child feeding may contribute to poor child feeding practices. Grandmothers influenced young mothers to introduce complementary foods earlier than six months. Grandmothers thought that breast milk alone could not be adequate for the growth and development of the baby. The influence of grandmothers on complementary feeding practices has also been reported in studies conducted in Northern Malawi and in Kenya [18, 19]. Due to strongly held beliefs that elderly women are custodians of culture, young mothers tended to adhere more to advice from elderly women than from medical personnel. This may explain why being a young mother was a significant risk factor associated with stunting. Some mothers reported that they could not produce adequate milk to satisfy the baby's needs and, therefore, introduced complementary foods before the age of six months. Introducing complementary foods before six months may cause under-nutrition due to low nutrient intake from complementary foods which are normally bulky with low nutrient density. The infants may also not digest the food efficiently since the digestive system is not yet matured enough to handle foods other than breast milk. Introducing complementary foods later than six months may lead to underfeeding since breast milk alone may no longer meet the nutrient requirements of the infants. This shows that to bring the desired behavior change in child feeding practices, different sources and channels of nutrition education should be used to promote good child feeding practices [20]. Nutrition education should also be targeted at teenage mothers, grandmothers and other family members who influence child feeding practices.

This study further showed that the majority of children did not meet the minimum required meal frequency and the meals were not diversified. Dietary diversity is a proxy for micronutrient density of foods and diets of low diversity cannot meet micronutrient requirements of the children. Diversified diets are also associated with improvement in intake of adequate nutrients that meet nutritional requirements of individuals and, therefore, improving household food security [14]. With limited variety of foods, it is not surprising that nutrient intake among the children was generally low (Table 5). These findings suggest that the majority of households were nutrition insecure and could not meet nutrition requirements of their children. Production of vegetables and rearing of small livestock such as poultry, rabbits and goats should be promoted in the study area to improve household food security and dietary nutrient intake among household members including children.

The World Health Organization recommends that children should be fed at least four times a day with three main meals and one or two snacks in between meals. Feeding children more frequently ensures adequate nutrient intake and good nutrition. Consumption of muscle foods, dairy products and eggs was low in the study area (Table 3). Since these are good sources of micronutrients, such as iron, calcium and vitamin A, low consumption may lead to micronutrient deficiency. Incorporating foods rich in iron and vitamin A into complementary foods may increase their nutrient density. Mothers should, therefore, be taught to add thinly shredded fish, meat, mashed green leafy vegetables and cooking oil to complementary foods to increase protein, iron, energy and vitamin $\mathrm{A}$ and $\mathrm{C}$ intake $[15,20]$. 
Mothers and caregivers in the study area were involved in different activities such as small- scale businesses and farming, which kept them away from home for long periods of time. Due to time constraints, the majority of mothers and caregivers could not afford to feed their children frequently and adequately. In some cases, children were cared for by older siblings who could not prepare proper complementary food for the children. A small proportion of mothers gave snacks to their children including bananas, boiled potatoes and baked food products. With low meal frequencies, the children could not get adequate energy and other nutrients to meet their daily requirements. Failure to provide minimum meal frequency is associated with stunting among children aged 6-23 months (Table 7). Training mothers on recommended meal frequencies for children of different age categories and providing them with skills in preparation and storage of complementary foods, which can be fed to children while they are not around may improve child feeding practices in the study area.

The common food given to children especially those aged six to eight months was porridge prepared from maize flour only because mothers believed that infants could not swallow other foods. Consumption of other foods increased among children aged 12 to 23 months (Table 3). At such ages mothers perceived that children were old enough to eat some finger foods and could easily digest other foods in addition to breast milk. These perceptions were also noted in studies conducted in Kenya and some parts of Malawi [8, 19]. It is well established that infants can ably eat porridge to which mashed vegetables, legumes or minced meat are added. Mothers and caregivers should be trained on diversification of food processing, preparation and consumption of mixed diets to increase nutrient intake of infants and young children.

Child morbidity affects nutritional status of children. This study showed that over periods of two days and two weeks before the study, children suffered from various illnesses such as diarrhoea, coughing and fever with difficult breathing which is a proxy for pneumonia. Sick children tend to reduce food intake due to loss of appetite and physiological changes that occur due to the illness. Diarrhoea and fever lead to reduced food and nutrient intakes in children and increased demand for nutrients [2]. If not managed properly, these illnesses can lead to weight loss and faltering of growth in children. To manage the diarrhoea, it was pleasing to learn that some mothers took the sick children to medical facilities for treatment; others gave children home- made fluids and medicines bought from local shops. Such actions assisted in reducing the severity of diarrhoea among the children. Diarrhoea is linked to poor hygienic handling of food and drinking water in the home. Mothers and caregivers should, therefore, be trained in good sanitation and hygienic handling of food and water to reduce prevalence of diarrhoea among the children.

The prevalence of stunting among children was very high with more male children being stunted than female children. Maternal perception on child development might have contributed to the differences in rates of stunting between male and female children. Mothers and caregivers indicated that male children developed quicker than female children in terms of meeting some developmental milestones such as beginning to stand and walking. Male children tended to be more active than female children and mothers paid more attention to female children in terms of frequency of feeding. Due to the same 
perception that male children developed faster than female children, breast feeding was terminated earlier in male than in female children. By being more active than female children, male children expended more energy than female children. The energy expenditure might have been worsened by low energy and nutrient intake due to early termination of breastfeeding.

The prevalence of stunting among children was significantly associated with young age of the mother, number of infants and young children in the household and introduction of solid, semi-solid or soft foods. Generally young mothers are resource constrained and may not ably take care of the child. Coupled with lack of experience and misinformation from grandmothers $[18,19]$, children are at high risk of stunting. This study showed that over one third of mothers had given birth to between 5 and 9 children; reflecting large family sizes. Most mothers aged between 21 and 34 years had more than one child under the age of five years to take care of. The high number of siblings in the households would lead to reduced family resources to care for each child, resulting in poor child feeding and stunting.

\section{CONCLUSION}

It was shown in this localized study in Dedza district of Central Malawi that prevalence of stunting is high among children aged 6 to 23 months. Being a teenage mother, age of introducing solid, semi-solid or soft food and number of young children in the household are significant independent predictors of stunting. Training mothers and caregivers on recommended age of introducing complementary food to a child, composition of such food, dangers of teenage pregnancies and importance of child spacing should form part of nutrition education in the study area. 


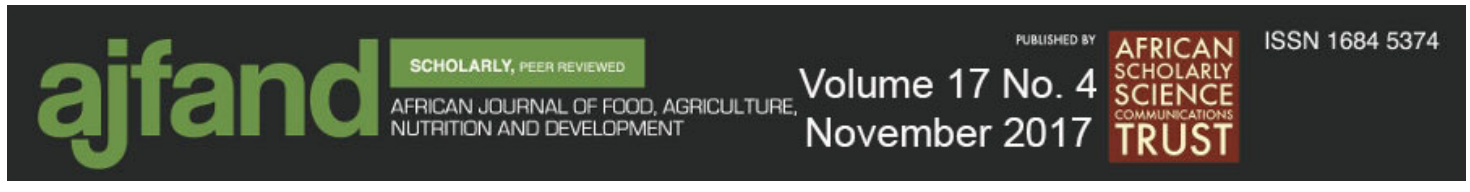

Table 1: Demographic characteristic of household members $(n=303)$

\begin{tabular}{|c|c|c|}
\hline Household Characteristics & (n) & Percentage \\
\hline \multicolumn{3}{|l|}{ Sex of household head } \\
\hline Male & 270 & 89.1 \\
\hline Female & 33 & 10.9 \\
\hline \multicolumn{3}{|l|}{$\begin{array}{l}\text { Marital status of household } \\
\text { head }\end{array}$} \\
\hline Married & 272 & 89.7 \\
\hline Single & 31 & 10.3 \\
\hline \multicolumn{3}{|l|}{$\begin{array}{l}\text { Marital status of } \\
\text { mother/caregiver }\end{array}$} \\
\hline Married & 239 & 88.1 \\
\hline Single & 36 & 11.1 \\
\hline $\begin{array}{l}\text { Mean age of household } \\
\text { head(years) }\end{array}$ & $32.3 \pm 10.6$ & \\
\hline $\begin{array}{l}\text { Mean age of } \\
\text { mother/caregiver (years }\end{array}$ & $26.5 \pm 7.0$ & \\
\hline Mean household size (SD) & $5.0 \pm 1.8$ & \\
\hline $\begin{array}{l}\text { Mean number of children } \\
\text { under five years of age }\end{array}$ & $1.4 \pm 0.6$ & \\
\hline $\begin{array}{l}\text { Average number of females } \\
\text { per household (SD) }\end{array}$ & $5.5 \pm 1.9$ & \\
\hline $\begin{array}{l}\text { Average number of males } \\
\text { per household (SD) }\end{array}$ & $4.9 \pm 1.8$ & \\
\hline $\begin{array}{l}\text { Average number of } \\
\text { dependents }(<15 \mathrm{yrs}+>64 \mathrm{yrs})\end{array}$ & $2.8 \pm 1.5$ & \\
\hline Dependency Ratio & 1.2 & \\
\hline
\end{tabular}




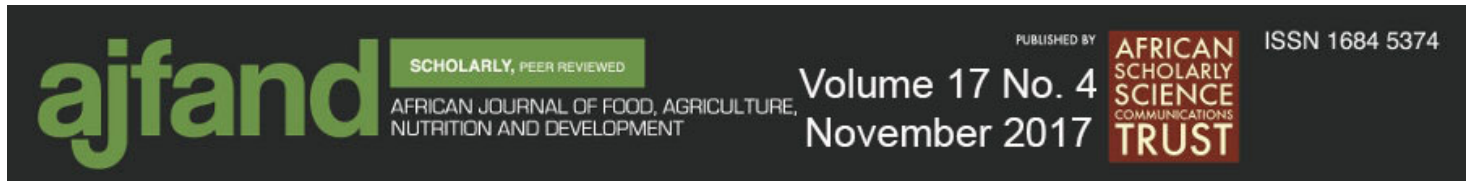

Table 2: Dietary diversity of mothers and caregivers by sex of household head

\begin{tabular}{lccc}
\hline Sex of Household head & \multicolumn{2}{c}{ Number of food groups consumed } & \\
\cline { 3 - 4 } & $\begin{array}{c}1-3 \\
\text { (No diversity) }\end{array}$ & $\begin{array}{c}4-5 \\
\text { (Minimum diversity) }\end{array}$ & $\begin{array}{c}\geq 6 \\
\text { (High diversity) }\end{array}$ \\
\hline Male $\quad(\mathrm{N}=270)$ & 37.4 & 43.7 & 18.9 \\
Female $(\mathrm{N}=33)$ & 51.1 & 39.4 & 9.1 \\
Total $\quad(\mathrm{N}=303)$ & 38.9 & 3.2 & 17.8 \\
\hline
\end{tabular}

Table 3: Food groups consumed by children of different age categories

\begin{tabular}{|c|c|c|c|c|c|}
\hline \multicolumn{6}{|c|}{ Age category of children in months } \\
\hline & $6-8$ & $9-11$ & $12-23$ & (Total) & P-Value \\
\hline \multicolumn{6}{|l|}{ Food group } \\
\hline Grains, roots and tubers $(\mathrm{N}=280$ & 88.6 & 97.0 & 92.8 & 92.7 & 0.170 \\
\hline Legumes and nuts $(\mathrm{N}=157)$ & 42.9 & 53.0 & 55.1 & 51.8 & 0.222 \\
\hline Dairy products $(\mathrm{N}=79)$ & 20.0 & 30.3 & 26.9 & 26.9 & 0.365 \\
\hline Fresh foods $(\mathrm{N}=33)$ & 4.3 & 12.1 & 13.2 & 10.9 & 0.126 \\
\hline Eggs $(\mathrm{N}=16)$ & 0.0 & 6.1 & 7.2 & 5.3 & 0.0074 \\
\hline Vitamin A rich vegetables $(\mathrm{N}=75)$ & 11.4 & 24.2 & 30.5 & 24.8 & 0.008 \\
\hline Other fruits and vegetables $(\mathrm{N}=118)$ & 11.4 & 39.4 & 50.3 & 38.9 & 0.000 \\
\hline
\end{tabular}

Table 4: Dietary diversity of children by age category $(n=303)$

\begin{tabular}{|l|c|c|}
\hline Age category of children & Minimum diversity (\%) & No diversity (\%) \\
\hline 6-8 months $(\mathrm{n}=70)$ & 2.9 & 97.1 \\
\hline 9-11 months $(\mathrm{n}=66)$ & 15.2 & 84.8 \\
\hline $12-23$ months $(\mathrm{n}=167)$ & 24.6 & 75.4 \\
\hline Total & 17.5 & 82.5 \\
\hline$\chi^{2}=16.41, \mathrm{p}<0.001$ & &
\end{tabular}

$\chi^{2}=16.41, \mathrm{p}<0.001$ 


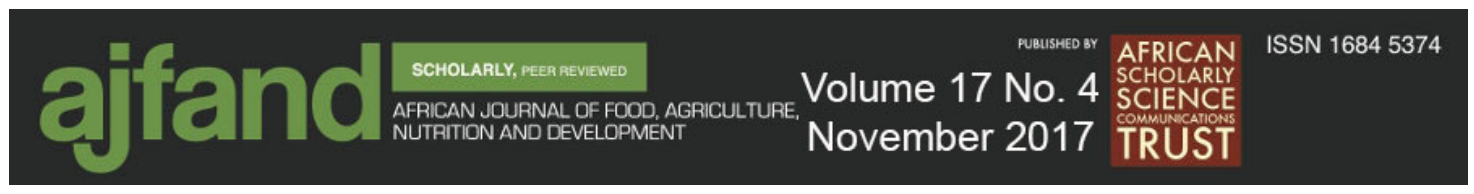

Table 5: Estimated intake of energy and macronutrients by age category of children $(\mathbf{n}=\mathbf{3 0 3})$

\begin{tabular}{|l|c|c|c|}
\hline Age category/Nutrient & RDA & Intake & \% of RDA \\
\hline 6-8 months (n=70) & & & \\
\hline Energy $(\mathrm{kcal})$ & 2036.3 & $815.12 \pm 771.25$ & 40.0 \\
\hline Protein $(\mathrm{g})$ & 60.1 & $20.35 \pm 22.27$ & 33.8 \\
\hline Fat $(\mathrm{g})$ & 69.1 & $9.87 \pm 9.37$ & 14.3 \\
\hline Vitamin A $(\mu \mathrm{g})$ & 600.0 & $95.44 \pm 330.40$ & 64.0 \\
\hline Iron $(\mathrm{mg})$ & 8.0 & $3.64 \pm 4.10$ & 435.5 \\
\hline 9-11 months(n=66) & & & \\
\hline Energy $(\mathrm{kcal})$ & 2036.3 & $944.7 \pm 65.1$ & 46.4 \\
\hline Protein $(\mathrm{g})$ & 60.1 & $21.7 \pm 17.0$ & 36.2 \\
\hline Fat $(\mathrm{g})$ & 69.1 & $10.3 \pm 7.9$ & 15.0 \\
\hline Vitamin A $(\mu \mathrm{g})$ & 600.0 & $425.0 \pm 324.5$ & 70.8 \\
\hline Iron $(\mathrm{mg})$ & 8.0 & $4.0 \pm 3.0$ & 49.6 \\
\hline 12-23 months $(\mathbf{n}=\mathbf{1 6 7})$ & & & \\
\hline Energy $(\mathrm{kcal})$ & 2036.3 & $1298.96 \pm 734.6$ & 64.0 \\
\hline Protein $(\mathrm{g})$ & 60.1 & $27.87 \pm 22.1$ & 45.9 \\
\hline Fat $(\mathrm{g})$ & 69.1 & $13.19 \pm 10.1$ & 19.1 \\
\hline Vitamin A $(\mu \mathrm{g})$ & 600.0 & $539.2 \pm 405.3$ & 80.5 \\
\hline Iron $(\mathrm{mg})$ & 8.0 & $5.0 \pm 3.4$ & 62.7 \\
\hline
\end{tabular}

Table 6: Nutritional status of children by age and by sex categories $(n=306)$

\begin{tabular}{|l|l|l|c|}
\hline \multicolumn{4}{|c|}{ Height for age\% (95\% CI) } \\
\hline AGE & $\begin{array}{l}<-3 \text { SD (severely } \\
\text { stunted) }\end{array}$ & $<-2$ SD (stunted) & $(\mathrm{N})$ \\
\hline $6-11$ & $10.2(4.6 \%-16.0 \%)$ & $36.7^{\mathrm{a}}(28.5 \%-46.1 \%)$ & 128 \\
\hline $12-23$ & $22.5(16.1 \%-28.9 \%)$ & $54.5^{\mathrm{b}}(46.9 \%-62.1 \%)$ & 178 \\
\hline TOTAL & $17.3(13 \%-21.9 \%)$ & $47.1(41.6 \%-53.1 \%)$ & 306 \\
\hline SEX & $22.7(16.0 \%-30.0 \%)$ & $54.5(47.0 \%-63.5 \%)$ & 154 \\
\hline Male & $11.8(6.4 \%-17.3 \%)$ & $39.5(31.4 \%-47.6 \%)$ & 152 \\
\hline Female & $17.3(13 \%-21.9 \%)$ & $47.1(41.6 \%-53.1 \%)$ & 306 \\
\hline TOTAL &
\end{tabular}

Values with different superscripts in the same column are significantly different $(p<0.05)$ from each other 


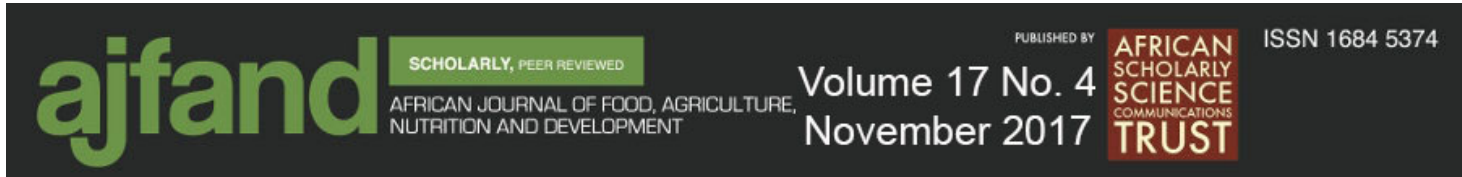

Table 7: Factors associated with stunting in children aged 6-23 months in Dedza district

\begin{tabular}{|c|c|c|c|c|}
\hline \multirow[t]{3}{*}{ Explanatory Variable } & \multicolumn{2}{|c|}{ Nutritional Status } & \multirow{3}{*}{ Adjusted OR $(95 \% \mathrm{CI})$} & \multirow{3}{*}{ P-value } \\
\hline & & & & \\
\hline & Normal (\%) & Stunted (\%) & & \\
\hline \multicolumn{5}{|l|}{ Maternal Level of Education } \\
\hline Primary school & $116(52.5)$ & $105(47.5)$ & $0.913(0.606-1.376)$ & 0.664 \\
\hline Secondary School and above & $15(53.6)$ & $13(46.4)$ & 1 & \\
\hline No formal education & $31(57.4)$ & $23(42.6)$ & 1 & \\
\hline \multicolumn{5}{|l|}{ Feeding practice } \\
\hline $\begin{array}{l}\text { Correct age of introducing solid, semi- } \\
\text { solid or soft food to child } \\
\text { - Yes } \\
\text { - No }\end{array}$ & $\begin{array}{l}129(52.9) \\
33(55.9)\end{array}$ & $\begin{array}{l}115(47.1) \\
26(44.1)\end{array}$ & $\begin{array}{l}* 0.138(0.22-0.88) \\
1\end{array}$ & 0.036 \\
\hline $\begin{array}{l}\text { Minimum dietary diversity } \\
\text { - Yes } \\
\text { - No }\end{array}$ & $\begin{array}{l}28(52.8) \\
137(54.8)\end{array}$ & $\begin{array}{l}25(47.2) \\
113(45.2)\end{array}$ & $\begin{array}{l}2.372(0.558-0.089) \\
1\end{array}$ & 0.242 \\
\hline $\begin{array}{l}\text { Minimum meal frequency } \\
\text { - Yes } \\
\text { - No } \\
\text { Minimum acceptable diet } \\
\text { - Yes } \\
\text { - No }\end{array}$ & $\begin{array}{l}32(11.3) \\
119(41.9) \\
75(26.6) \\
75(26.6)\end{array}$ & $\begin{array}{l}19(6.7) \\
114(40.1) \\
65(23.0) \\
67(23.8)\end{array}$ & $\begin{array}{l}0.507(0.191-1.342) \\
1 \\
1.095(0.556-2.516) \\
1\end{array}$ & $\begin{array}{l}0.171 \\
0.794\end{array}$ \\
\hline \multicolumn{5}{|l|}{ Household Characteristics } \\
\hline $\begin{array}{l}\text { Number of young children in the home } \\
\leq 2 \text { children } \\
\geq 3 \text { children }\end{array}$ & $\begin{array}{l}90(46.9) \\
71(64.5)\end{array}$ & $\begin{array}{l}102(53.1) \\
39(35.5)\end{array}$ & $\begin{array}{l}* 2.548(1.304-4.981) \\
1\end{array}$ & 0.006 \\
\hline \multicolumn{5}{|l|}{ Mother's age category (Years) } \\
\hline$\leq 19$ & $13(31.7)$ & $28(68.3)$ & $* 1.265(0.379-0.724)$ & 0.046 \\
\hline $20-24$ & $56(50.5)$ & $55(49.5)$ & 1 & \\
\hline$\geq 25$ & $48(69.6)$ & $21(30.4)$ & 1 & \\
\hline
\end{tabular}

*indicates significant $(\mathrm{p}<0.05)$ 


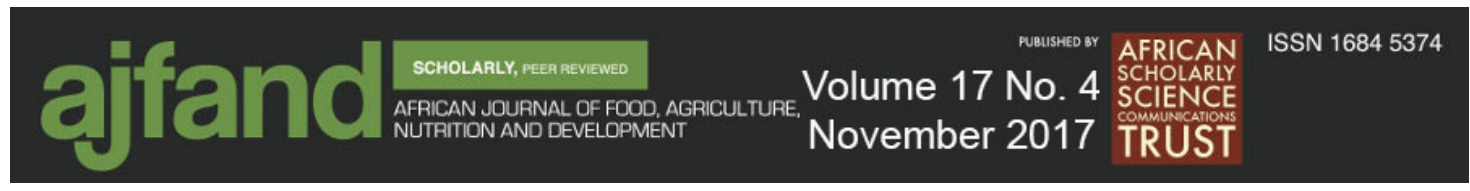

\section{REFERENCES}

1. World Health Organization Media Centre. Infant and Young Child Feeding Fact Sheet, 2016.

2. National Statistical Office and ICF Macro. Malawi Demographic and Health Survey. National Statistical Office, Zomba, 2015.

3. Malawi Government. The 2009 National Micronutrient Survey, Office of the President and Cabinet, Lilongwe, 2010.

4. The World Health Organization. Indicators for assessing infant and young child feeding practices, Part 3 Country profiles, 2010.

5. Malawi Government. Health Sector Strategic Plan 2011-2016: Moving towards equity and quality, Ministry of Health, Lilongwe, 2011.

6. United Nations Children's Fund (UNICEF). Conceptual Framework of Causes of Malnutrition, 1997.

7. Hotz C and RS Gibson Complementary feeding Practices and dietary intakes from complementary foods amongst weanlings in rural Malawi. European Journal of Clinical Nutrition, 2001; 55:841-849.

8. Mtimuni BM, Nkhoma O, Katundu M and NC Geresomo Dietary Survey, Ntchisi ADP, Malawi: Regional Programme Fisheries and HIV/AIDS in Africa: 2010. Investing in Sustainable Solutions the World Fish Center and the Food and Agriculture Organization of the United Nations (FAO).

9. Picado JI and BM Mtimuni Consulting with Caregivers. Formative research to determine the barriers and facilitators to optimal Infant and Young Child feeding in three regions of Malawi. USAID's Infant and Young Child Nutrition Project, 2010 .

10. Malawi Government and United Nations Children Fund (UNICEF) 1000 Special Days: National Nutrition Education and Communication Strategy for preventing child stunting in Malawi 2011 - 2016, Office of the President and Cabinet, 2011.

11. Golden M, Seaman $\mathbf{J}$ and $\mathbf{J}$ Erhardt Emergency Nutrition Assessment for Standard Monitoring and Relief in Transition (SMART), 2011.

12. Gibson RS Principles of Nutritional Assessment. Second Edition, Oxford University Press, 2005.

13. World Health Organization. Multicenter Growth Reference Study Group. WHO child growth standards based on length/height, weight and age. ActaPaediatr Suppl. 2006; 450:76-85. 


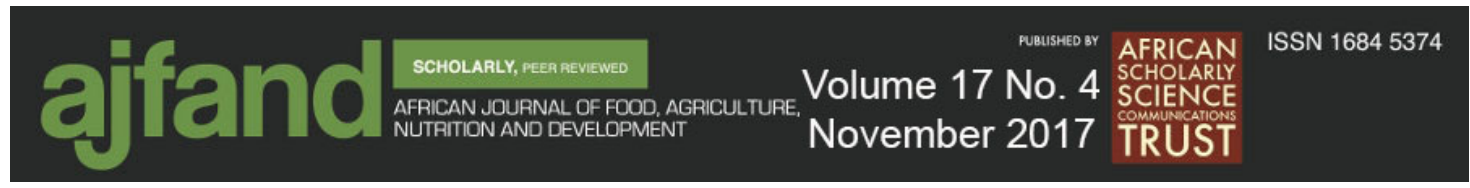

14. Food and Agriculture Organization. Guidelines for measuring household and individual dietary diversity. Version 2: Rome, Italy, 2007.

15. Swindale A and P Bilinsky Household Dietary diversity Score (HDDS) for Measurement of Household food Access: Indicator Guide, Food and Nutrition Technical Assistance, The Journal of Nutrition, 2005; Vol. 138 No. 12: 244853.

16. The National Statistical Office (NSO). 2008 Malawi Population and Housing Census, Zomba, Malawi, 2009.

17. Agedew $\mathbf{E}$ and $\mathbf{T}$ Chane Prevalence of Stunting among Children Aged 6-23 Months in Kemba Woreda, Southern Ethiopia: A Community Based CrossSectional Study. Hindawi Publishing Corporation, Advances in Public Health Volume 2015, Article ID 164670, http://dx.doi.org/10.1155/2015/164670. Accessed on 14th May 2016.

18. Bezner Kerr R, Dakishon $\mathbf{L}$ and L Shumba "We grandmothers know plenty". Breastfeeding, complementary feeding and the multifaceted role of grandmothers in Malawi. Social Science Medicine; 2008; 66(5):1095-1105.

19. Nduati R, Arum S and E Kageha Beliefs and attitudes around infant and young child feeding in Kenya: Rapid Qualitative Assessment. Ministry of Health, 2011, Kenya.

20. Food and Agriculture Organization. Agriculture, food and nutrition for Africa. A resource book for teachers of Agriculture, 1997. Information Division, Food and Agriculture Organization of the United Nations. Viale Delle Terme di Caracalla, 00100, Rome Italy.

21. Latham MC Human Nutrition in the Developing World. $4^{\text {th }}$ Edition, Food and Agriculture Organization, Rome. 1997. Food and Nutrition Series-No. 29. 